\title{
Cigarette Smoking, Body Mass and Other Risk Factors for Fractures of the Hip in Women
}

\author{
CARLO LA VECCHIA, *** EVA NEGRI," FABIO LEVI** AND JOHN A BARON†
}

\begin{abstract}
La Vecchia C (Istituto di Ricerche Farmacologiche 'Mario Negri', via Eritrea 62, 20157 Milano, Italy), Negri E, Levi F and Baron JA. Cigarette smoking, body mass and other risk factors for fractures of the hip in women. International Journal of Epidemiology 1991; 20: 671-677.

Determinants of hip fractures were assessed using data from a network of hospital-based case-control studies from northern Italy. For the present analysis, cases were 209 women with fractures of the hip/proximal femur (aged 29 to 74 , median ege 62) admitted to a network of teaching and general hospitals in the greater Milan area; controls were 1449 women, aged 25 to 74 (median age 55), admitted for non-traumatic, acute conditions to the same network of hospitals. There was a strong direct association with smoking, the relative risk (RR) being significantly and similarly elevated both in ex- and in current smokers (RR 1.7 and 1.5 respectively) which rose to 2.4 for 25 or over cigarettes per day. The risk was associated with duration of smoking and apparently greater in post-menopausal women. Two factors showed significant inverse associations with hip fractures: relative weight, with relative risks of $0.5,0.4$ and 0.3 in subsequent categories of body mass index as compared with thinner ones, and the use of oestrogen replacement treatment (multivariate $R R=0.4,95 \%$ confidence interval $(\mathrm{Cl}): 0.2-1.1)$. No association was observed with education or social class, selected indicator foods or alcohol consumption (RR for the highest consumption level = 1.0). The effects of smoking and body mass index appeared independent: compered with never smoking heavier women, the RR for smoking thin women was 4.6. Thus, this case-control study of hip fractures in a predominantly post-menopausal population of Italian women showed a strong association with smoking and appreciable protection from heavier body mass index and the use of oestrogen replacement treatment.
\end{abstract}

Hip fractures, whose determinants are only partly defined and quantified, are a major cause of morbidity and mortality in older women. It is known, for instance, that menopausal oestrogen therapy reduces the incidence of hip fractures, and an inverse relationship with weight has been observed in several studies. ${ }^{!-3}$ In contrast, the roles of smoking, alcohol or diet are less clear.

Investigations of the relationship between cigarette smoking and the risk of hip fracture in women, for instance, have reached differing conclusions. Some studies have found risks of fracture two to three times higher in women who smoke as compared with never smokers, ${ }^{1-3}$ but others showed no, or only a weak, relationship. $\leftrightarrow$

While some of the studies may have failed to find an association because of poor power, the analysis of both

\footnotetext{
"Istituto di Ricerche Farmacologiche 'Mario Negri', Via Eritrea 62 , 20157 Milano, Italy.

" Instıtut universitaire de médecine sociale et préventive, Bugnon 17, 1005 Lausanne, Switzerland.

tDepartment of Community and Family Medicine, Dartmouth Medical School, 03756 Hanover, New Hampshire, USA.
}

sexes combined, or other artifacts, conflicting results from analyses apparently free of these problems remain. ${ }^{10}$

One explanation for these differences may be the inability of most of the studies to control for the effects of factors such as alcohol use or diet. Another possibility is that the effect of smoking is different in various groups of women, e.g. those at high or low risk of fracture because of body habitus, oestrogen use, etc. Such modification of the effect of cigarette smoking has been noted in some studies of endometrial cancer, in which smoking may have a particularly strong 'antioestrogenic' effect among women who are post-menopausal, obese or who take menopausal oestrogens. ${ }^{10}$ None of the studies previously reported have investigated in detail similar differences in the effect of smoking on hip fracture risk.

To provide further information on this important public health issue, we have considered smoking and other major risk factors for hip fractures using data from a case-control study conducted in northern Italy.

\section{SUBJECTS AND METHODS}

The data were derived from the control group of an 
ongoing series of case-control studies of breast and female genital cancers conducted since 1983 in northern Italy. ${ }^{11}$ In the general study design, trained interviewers identified and questioned women aged 24-74 years admitted for the neoplasms under consideration or for a wide spectrum of acute, non-neoplastic conditions.

\section{Cases}

For the present analysis, cases were women below age 75 admitted for fractures of the hip/proximal femur to the Ospedale Maggiore (which includes the four largest teaching and general hospitals in Milan) and several university orthopaedic clinics. A total of 209 cases, aged 29 to 74 (median age, 62 years) was interviewed.

\section{Controls}

The comparison group consisted of women admitted for acute conditions (other than trauma) to the same network of hospitals as the cases. The catchment areas for cases and controls were comparable (over $95 \%$ of cases and $90 \%$ of controls resided in the same region, Lombardy). A total of 1449 controls, aged 25 to 74 (median age, 55 years) was included in the present analyses. Of these, $23 \%$ had non-traumatic orthopaedic conditions (mostly low back pain and disc disorders), $43 \%$ were admitted for acute surgical conditions (mostly abdominal, such as acute appendicitis or strangulated hernia), and $34 \%$ had other illnesses, such as ear, nose and throat or dental disorders. Subjects admitted to hospital with an admission diagnosis of smoking- or alcohol-related disease were specifically excluded from the comparison group. Subjects admitted for other diagnoses, but with a past history of major smoking- or alcohol-related diagnoses, were not excluded. Overall less than $3 \%$ of the women approached ( 8 cases, 38 controls) refused to participate. The present report is based on data collected before June 1989.

A structured questionnaire was used to obtain information on sociodemographic factors, general characteristics and habits, including alcohol, coffee and tobacco consumption. Smoking status included duration and average number of cigarettes smoked per day. Other items included consumption of a few selected indicator foods; a problem-oriented medical history, with special emphasis on hormonal and gynaecological features; obstetric data; history of lifetime use of oral contraceptives, menopausal replacement treatment, and other therapeutic hormone treatments.

Post-menopausal women were defined as those with surgical menopause, plus those whose menstrual cycles had stopped more than one year previously. The definition of social class was based on the head of the household's occupation, using a classification derived from that used by the British Registrar General. ${ }^{12}$ Questions on alcohol included the number of days per week each type of alcoholic beverage (wine, beer, spirits) was consumed, the average number of drinks per day and the duration of the habit in years. The short dietary section included the frequency of consumption (before the onset of the disease which led to the index admission) of ten selected indicator foods (milk, dairy products, meat, fish, liver, eggs, ham and salami, carrots, green vegetables, and fruit), plus simple subjective scores for whole grain bread or pasta, butter, margarine and oil.

\section{Data Analysis}

The odds ratio (relative risk: RR) of hip fracture, together with the corresponding $95 \%$ approximate confidence intervals (CI), ${ }^{13}$ were first computed from data stratified for quinquennia of age by means of the Mantel-Haenszel procedure. ${ }^{14}$ For multiple levels of exposure, significance was assessed by the linear trend test. ${ }^{15}$ Further, in order to allow simultaneously for the effect of several potential confounding factors, multiple logistic regression, with maximum likelihood fitting, was used. ${ }^{13-16}$ Included in the regression equations were terms for age (as a continuous variable), area of residence, years of education, smoking, body mass index, use of oestrogen replacement treatment, alcohol consumption and (when applicable) menopausal status.

\section{RESULTS}

Cases and controls were similar in education (64\% of the cases versus $63 \%$ of the controls reported less than seven years of education, $17 \%$ versus $14 \%$ reported 12 or more) and social class (10\% of the cases versus $7 \%$ of the controls were in the higher social classes I or II, $35 \%$ versus $41 \%$ in the lower classes IV or V).

Table 1 considers the relationship between hip fractures and smoking habits. The RR was significantly and similarly elevated both in ex- and in current smokers, with point estimates of 2.2 and 1.6 , respectively. A strong diet association was observed with number of cigarettes per day, with RR of 1.3 for less than $15 /$ day, 2.0 for 15 to $24 /$ day and 2.8 for 25 or over cigarettes per day. Likewise, the risk of hip fracture was directly related to duration of smoking, with an age-adjusted point estimate of 1.9 for 20 years or more duration. These associations were not materially modified by simultaneously allowing for major potential confounding factors, using multiple logistic regression. 
TABLE 1 Distribution of 209 cases of hip fracture and 1449 controls according to smoking habits. Milan, Italy 1983-1989

\begin{tabular}{|c|c|c|c|c|}
\hline & \multirow[b]{2}{*}{ Hip fracture } & \multirow[b]{2}{*}{ Controls } & \multicolumn{2}{|c|}{ Relative risk $(95 \% \mathrm{Cl})$} \\
\hline & & & Mantel-Haenszel* & $\begin{array}{l}\text { Multiple logistic } \\
\text { regression ** }\end{array}$ \\
\hline \multicolumn{5}{|l|}{ Smoking status } \\
\hline Never smokers & 135 & 1004 & $1 \#$ & $1 \neq$ \\
\hline Exsmokers & 51 & 353 & $\begin{array}{c}2.2 \\
(1.3-3.7)\end{array}$ & $\begin{array}{c}1.7 \\
(1.0-3.0)\end{array}$ \\
\hline Current smokers & 23 & 92 & $\begin{array}{c}1.6 \\
(1.0-2.3)\end{array}$ & $\begin{array}{c}1.5 \\
(1.0-2.1)\end{array}$ \\
\hline \multicolumn{5}{|c|}{ Number of cigarettes/day } \\
\hline$<15$ & 38 & 266 & $\begin{array}{c}1.3 \\
(0.9-2.0)\end{array}$ & $\begin{array}{c}1.2 \\
(0.8-1.8)\end{array}$ \\
\hline $15-24$ & 28 & 149 & $\begin{array}{c}2.0 \\
(1.2-3.1)\end{array}$ & $\begin{array}{c}1.7 \\
(1.1-2.9)\end{array}$ \\
\hline$\geqslant 25$ & 8 & 30 & $\begin{array}{c}2.8 \\
(1.2-63)\end{array}$ & $\begin{array}{c}24 \\
(1.0-5.9)\end{array}$ \\
\hline$x_{1}^{2}($ trend $)$ & & & $\begin{array}{c}13.98 \\
(p<0001)\end{array}$ & $\begin{array}{c}7.03 \\
(p=0.008)\end{array}$ \\
\hline \multicolumn{5}{|c|}{ Duration of smoking (years) } \\
\hline$<20$ & 16 & 187 & $\begin{array}{c}1.1 \\
(0.6-19)\end{array}$ & $\begin{array}{c}1.2 \\
(07-2.2)\end{array}$ \\
\hline$\geqslant 20$ & 58 & 258 & $\begin{array}{c}1.9 \\
(1.3-2.7)\end{array}$ & $\begin{array}{c}1.8 \\
\left(\begin{array}{lll}1 & 2-2 & 5\end{array}\right)\end{array}$ \\
\hline$x_{1}^{2}($ trend $)$ & & & $\begin{array}{c}14.03 \\
(p<0001)\end{array}$ & $\begin{array}{c}13.01 \\
(p<0001)\end{array}$ \\
\hline
\end{tabular}

- Adjusted for age in decades.

** Including terms for age, area of residence, education, body mass index, menopausal status, use of oestrogen replacement treatment and alcohol consumption

\#Reference category.

Other factors considered in this study are presented in Table 2. There was a significant trend in protection with increasing body mass index reaching a RR of 0.3 in the most obese group relative to the leanest. The reduced risk with oestrogen replacement treatment did not reach conventional statistical significance, possibly because of small absolute numbers of exposed subjects ( 5 cases, 52 controls). Nonetheless, the multivariate RR was 0.4 (95\% CI: 0.2-1.1) (Table 2).

No association was observed between hip fracture risk and levels of alcoholic beverage intake, with RRs being close to unity in each intake category (Table 2). Other aspects of diet were investigated in terms of a short list of 14 selected indicator foods, including important sources of calcium such as milk, cheese or butter: none of these was related to hip fractures either.

Table 3 gives the menopause-specific rates for the three major factors of interest. The small number of pre-menopausal cases precludes more precise inferences but in general the pre- and post-menopausal estimates were similar for smoking, weight, and alcohol intake, and even the moderate differences in RRs between pre- and post-menopausal women may be due to cohort effects in risk factor exposure. The interaction terms between menopausal status and the exposure variables were not statistically significant.
The interaction between smoking status and body mass index is considered in Table 4. The RRs increased in each stratum of smoking across decreasing levels of body mass index, and were higher for ever smokers than for never smokers in each stratum of body mass index. Thus, the effect of the two factors appeared roughly independent: compared with never smoking, heavier women, the estimated RR for thinner, ever smokers was 4.6 .

\section{DISCUSSION}

This case-control study of hip fractures in a predominantly post-menopausal population of women from northern Italy showed a strong association with smoking, as well as appreciable inverse associations with heavier body mass and the use of oestrogen replacement treatment. No relationship emerged with socioeconomic factors, alcohol intake or selected indicator foods.

Our findings suggest a stronger relationship between cigarette smoking and the risk of hip fracture than has been reported previously. This may in part have been due to our relatively large sample size, our focus on women only, and our study of incident cases of one fracture type. While some studies (e.g. on US Nurses) ${ }^{17}$ have suggested that pre-or peri-menopausal 
TABLE 2 Distribution of 209 cases of hip fracture and 1449 controls according to body mass index, oestrogen replacement treatment use and total alcoholic beverage consumption. Milan, Italy $1983-1989$

\begin{tabular}{|c|c|c|c|c|}
\hline & & & Relativ & $\% \mathrm{Cl})$ \\
\hline & Hip fracture & Controls & Mantel-Haenszel* & $\begin{array}{l}\text { Multuple logistic } \\
\text { regression** }\end{array}$ \\
\hline \multicolumn{5}{|c|}{ Body mass index $\left(\mathrm{kg} / \mathrm{m}^{2}\right)$} \\
\hline$<20$ & 43 & 180 & $1 \#$ & $1 *$ \\
\hline $20-24$ & 95 & 680 & $\begin{array}{c}0.5 \\
(0.3-0.7)\end{array}$ & $\begin{array}{c}0.5 \\
(0.3-0.8)\end{array}$ \\
\hline $25-29$ & 59 & 450 & $\begin{array}{c}0.4 \\
(0.2-0.6)\end{array}$ & $\begin{array}{c}0.4 \\
(0.2-0.6)\end{array}$ \\
\hline$>30$ & 12 & 134 & $\begin{array}{c}0.3 \\
(0.1-0.5)\end{array}$ & $\begin{array}{c}0.3 \\
(0.1-0.5)\end{array}$ \\
\hline $\begin{array}{l}\text { Unidentified } \\
\chi_{1}^{2} \text { (trend) }\end{array}$ & - & 5 & $\begin{array}{c}- \\
22.30 \\
(p<0.001)\end{array}$ & $\begin{array}{c}- \\
16.38 \\
(p<0.001)\end{array}$ \\
\hline \multicolumn{5}{|c|}{$\begin{array}{l}\text { Use of oestrogen } \\
\text { replacement treatment }\end{array}$} \\
\hline Never & 204 & 1397 & $1 \#$ & $1=$ \\
\hline Ever & 5 & 52 & $\begin{array}{c}0.6 \\
(0.2-1.4)\end{array}$ & $\begin{array}{c}0.4 \\
(0.2-1 \quad 1)\end{array}$ \\
\hline \multicolumn{5}{|c|}{$\begin{array}{l}\text { Total alcoholic consumption } \\
\text { (drinks per day) }\end{array}$} \\
\hline 0 & 75 & 534 & $1 *$ & $1 \%$ \\
\hline$<2$ & 55 & 461 & $\begin{array}{c}0.8 \\
\left(\begin{array}{lll}0 & 5-1 & 1\end{array}\right)\end{array}$ & $\begin{array}{c}0.7 \\
(05-1.1)\end{array}$ \\
\hline $2-3$ & 64 & 354 & $\begin{array}{c}1.3 \\
(09-1.8)\end{array}$ & $\begin{array}{c}1.2 \\
(08-1.8)\end{array}$ \\
\hline$>3$ & 15 & 100 & $\begin{array}{c}11 \\
(0.6-2.0)\end{array}$ & $\begin{array}{c}1.0 \\
(05-1.8)\end{array}$ \\
\hline$x_{1}^{2}$ (trend) & & & $\begin{array}{r}051 \\
\text { (n.s.) }\end{array}$ & $\begin{array}{r}0.43 \\
\text { (n.s.) }\end{array}$ \\
\hline
\end{tabular}

*Adjusted for age in decades.

* Including terms for age, area of residence, education, smoking, body mass index, menopausal status, use of oestrogen replacement treatment and alcohol consumption.

\# Reference category.

smokers are not at increased risk of hip and forearm fractures considered together, our data are the first to report on hip fracture risks in both pre- and postmenopausal women.

There has been essentially no previous investigation of the risks of hip fracture in former smokers. Our data suggest that cessation of smoking does not result in a lessening of risk after 20 years of exposure. This implies that smoking may be associated with changes that are permanent, such as a reduction in bone mass. This might be expected, if prolonged smoking resulted in prolonged periods of relative oestrogen-deficiency. This persistent effect is consistent with other female hormone-mediated effects on bone metabolism, ${ }^{10-18}$ although limited direct epidemiological evidence is available on the topic.

The use of menopausal replacement treatment was uncommon in our study population, hampering our ability to study its effects. However, our results, though not statistically significant, are in line with previous evidence indicating an appreciable protective effect on the risk of hip fractures. ${ }^{19-22}$

The inverse relation with body weight was one of the strongest associations to emerge from this study. Again, this has been repeatedly observed in previous studies and has been explained either in terms of hormonal and metabolic correlates of greater body mass, of greater bone mass in heavier women, or of physical protection during a fall by adipose tissue. ${ }^{1-3.7}$

It is of interest that the inverse relationship with body mass index was of similar magnitude in never and ever smokers, suggesting that the effects of these two major determinants of hip fracture risk act independently on relative risk. The public health implications 
TABLE 3 Menopause-specific relative risks* in relation to selected variables. Milan, Iraly, 1983-89

\begin{tabular}{|c|c|c|}
\hline & $\begin{array}{l}\text { Pre-menopause } \\
\text { ( } 24 \text { cases, } \\
569 \text { controls) }\end{array}$ & $\begin{array}{l}\text { Post-menopause } \\
\text { (185 cases, } \\
880 \text { controls) }\end{array}$ \\
\hline \multicolumn{3}{|l|}{ Smoking status } \\
\hline Never smokers & $1 *$ & $1 *$ \\
\hline Exsmokers & - & $\begin{array}{c}2.0 \\
(1.1-3.5) \dagger\end{array}$ \\
\hline Current smokers & $\begin{array}{c}1.4 \\
(0.6-3.3)\end{array}$ & $\begin{array}{c}1.7 \\
(1.0-3.0)\end{array}$ \\
\hline \multicolumn{3}{|c|}{ Number of cigarettes/day } \\
\hline$<15$ & $\begin{array}{c}1.2 \\
(0.3-4.5)\end{array}$ & $\begin{array}{c}1.3 \\
(0.8-20)\end{array}$ \\
\hline $15-24$ & $\begin{array}{c}2.0 \\
(0.7-57)\end{array}$ & $\begin{array}{c}1.6 \\
(0.9-2.9)\end{array}$ \\
\hline$\geq 25$ & $\begin{array}{c}2.0 \\
(0.3-22.0)\end{array}$ & $\begin{array}{c}2.6 \\
(1.0-7.0)\end{array}$ \\
\hline$x_{1}^{2}($ trend $)$ & $\begin{array}{r}2.68 \\
(\mathrm{n} \mathrm{s.)})\end{array}$ & $\begin{array}{c}5.79 \\
(\mathrm{p}=0.02)\end{array}$ \\
\hline \multicolumn{3}{|c|}{ Duration of smoking (years) } \\
\hline$<20$ & $\begin{array}{c}1.4 \\
(0.5-30)\end{array}$ & $\begin{array}{c}11 \\
(0.5-2.3)\end{array}$ \\
\hline$\geq 20$ & $\begin{array}{c}1.6 \\
(0.6-4.1)\end{array}$ & $\begin{array}{c}2.0 \\
(1.3-3.0)\end{array}$ \\
\hline$x_{2}^{2}$ (trend) & $\begin{array}{l}1.94 \\
\text { (n.s) }\end{array}$ & $\begin{array}{c}12.69 \\
(p<0001)\end{array}$ \\
\hline \multicolumn{3}{|c|}{ Body mass index $\left(\mathrm{kg} / \mathrm{m}^{2}\right)$} \\
\hline$<20$ & $1 \#$ & $1 \#$ \\
\hline $20-24$ & $\begin{array}{c}04 \\
(0.2-1.1)\end{array}$ & $\begin{array}{c}0.5 \\
(0.3-0.7)\end{array}$ \\
\hline $25-29$ & $\begin{array}{c}0.4 \\
(0.1-1.5)\end{array}$ & $\begin{array}{c}0.3 \\
(0.2-0.5)\end{array}$ \\
\hline$\geq 30$ & $\begin{array}{c}03 \\
(0.03-2.8)\end{array}$ & $\begin{array}{c}0.2 \\
(0.1-0.5)\end{array}$ \\
\hline$x_{1}^{2}($ trend $)$ & $\begin{array}{r}1.57 \\
\text { (n.s.) }\end{array}$ & $\begin{array}{c}20.92 \\
(p<0.001)\end{array}$ \\
\hline \multicolumn{3}{|l|}{$\begin{array}{l}\text { Alcohol consumption } \\
\text { (drinks per day) }\end{array}$} \\
\hline 0 & $1 \#$ & $1 *$ \\
\hline$<2$ & $\begin{array}{c}0.4 \\
(0.1-1.5)\end{array}$ & $\begin{array}{c}0.8 \\
(05-1.1)\end{array}$ \\
\hline $2-3$ & $\begin{array}{c}13 \\
(0.5-3.4)\end{array}$ & $\begin{array}{c}1.2 \\
(0.8-1.8)\end{array}$ \\
\hline$>3$ & 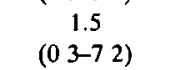 & $\begin{array}{c}1.0 \\
(0.5-1.8)\end{array}$ \\
\hline$x_{1}^{2}($ trend $)$ & $\begin{array}{r}0.66 \\
\text { (n.s.) }\end{array}$ & $\begin{array}{r}0.22 \\
(\text { n.s. })\end{array}$ \\
\hline
\end{tabular}

*Estimates from multiple logistic regression equations including terms for age, area of residence, education, body mass index, alcohol consumption and, in turn, each one of the smoking variables.

* Reference category.

$195 \%$ confidence interval of the relative risk estimates is given in parentheses.

of the over fourfold elevated risk of hip fractures for thinner and smoking women is clear.

The absence of an association with alcohol intake is at variance with observations made chiefly on North American populations. ${ }^{4,23,24}$ This is, however, not totally surprising, in view of the different pattern of alcohol consumption in Italy. Here, moderate amounts are commonly drunk by women during meals ${ }^{25}$ and over $60 \%$ of the control population drank some alcohol. This pattern of alcohol use is probably neither a major risk factor for injuries (including falls) nor a general indicator of risk-taking behaviour.

Likewise, the absence of protection by milk, cheese, butter and other calcium-containing foods is in agreement with recent studies from Britain, ${ }^{3.20}$ although investigations from California ${ }^{3}$ and Hong $\mathrm{Kong}^{8}$ suggested that calcium was inversely related to the risk in hip fractures. The latter finding was attributed to the lower average calcium intake in Hong Kong, but there is no defined evidence on the calcium/hip fracture issue in western countries.

The present study is a typical hospital-based casecontrol investigation and, consequently, has all its relative strengths and weaknesses. ${ }^{27}$ It is unlikely that the use of hospital controls led to overestimation of the tobacco-related risk; on the contrary an elevated prevalence of smoking in hospital controls is often suspected. Since obesity is related to several diseases, ${ }^{28}$ it is possible that the inverse association with relative weight is amplified by the use of hospital controls, but this can hardly account for the large associations observed in this study. In relation to general sources of bias, cases and controls were drawn from institutions covering comparable catchment areas and the participation rate was practically complete (although the study was not population-based and hence did not attempt to cover all hip fractures). Other traumatic conditions were excluded, and allowing for a number of potentially important covariates did not appreciably modify the risk estimates. Smoking-or alcohol-related diseases (such as bronchitis; emphysema or any other chronic respiratory disease; liver cirrhosis; ischaemic heart disease; gastro-duodenal ulcer) were excluded

TABLE 4 Interaction berween smoking and body mass index on the risk of hip fractures. Milan, Italy $1983-89$

\begin{tabular}{lcc}
\hline & \multicolumn{2}{c}{ Relative risk estimates* for } \\
\cline { 2 - 3 } & Never smokers & Ever smokers \\
\hline $\begin{array}{l}\text { Body mass index }\left(\mathrm{kg} / \mathrm{m}^{2}\right) \\
>25\end{array}$ & $1 \neq$ & 1.6 \\
& $(51: 453) \dagger$ & $(20: 131)$ \\
$20-24$ & 1.5 & 1.6 \\
& $(66: 448)$ & $(29: 232)$ \\
$<20$ & 2.4 & 4.6 \\
& $(18: 100)$ & $(25: 80)$ \\
\hline
\end{tabular}

"Estimates from multiple logistic regression equations including terms for age, area of residence, education, menopausal status, use of oestrogen replacement treatment and alcohol consumption.

\# Reference category.

tNumber of cases: number of controls are given in parentheses 
only if they represented the admission diagnoses. These exclusions are routinely adopted in the present case-control surveillance scheme, and the proportion of subjects excluded varies in different types of wards, but is systematically larger in medical than in surgical or other specialty wards. Although these exclusion criteria may indirectly bias the control group towards fewer smokers, exclusion of doubtful diagnoses and allowing for the risk factors responsible for potential bias in the analysis is generally considered as a reasonable approach for control selection and data analysis. ${ }^{29-31}$

The observation that most of the multivariate RRs (and specifically that of smoking and body mass index) were not materially different from those adjusted for age only is both reassuring and interesting, since it further confirms that the major identified risk factors are independent, at least in terms of RRs. Indeed, the slightly lower nisk estimates for smoking after multivariate analysis may be due to the inverse correlation between smoking and body mass index, and hence to consequent overadjustment.

In conclusion, our study clarifies the effects of cigarette smoking on hip fracture risk, and confirms previous studies regarding the impact of thin body habitus and oestrogen therapy. Our findings regarding alcohol intake suggest that further study of this exposure is required in societies with widespread moderate alcohol use.

\section{ACKNOWLEDGEMENTS}

This work was conducted within the framework of the CNR (Italian National Research Council) Applied Projects 'Oncology' (Contract No. 87.01544.44) and 'Risk Factors for Disease'. The contribution of the Italian Association for Cancer Research and the Italian League Against Tumours, Milan, Italy and the Europe against Cancer Programme of the Commissions of the European Communities are gratefully acknowledged.

\section{REFERENCES}

' Paganini-Hill A, Ross R K. Gerkins V R, Henderson B E, Arthur $M$, Mack T M. Menopausal estrogen therapy and hip fractures. Ann Iniem Med 1981; 95: 28-31.

2 Williams A R, Weiss N S, Ure CL, Ballard J, Daling J R. Effect of weight, smoking, and estrogen use on the risk of hip and forearm fractures in postmenopausal women. Obstet Gyencol 1982; 60: 695-49.

${ }^{3}$ Cooper C, Barker D J P, Wickham C. Physical activity, muscle strength, and calcium intake in fracture of the proximal femur in Britain. Br Med J 1988; 297: 1443-6.

4Felson D T, Kiel D P, Anderson J J, Kannel W B. Alcohol consumption and hip fracures: the Framingham Study. Am J Epidemiol 1988; 128: 1102-10.

'Holbrook T L, Barrett-Connor E, Wingard E L. Dietary calcium and nsk of hip fracture: 14-year prospective population study. Lancet 1988; ii: 1046-49.

${ }^{6} \mathrm{Kreiger} \mathrm{N}$, Hildreth S. Re: Cigarette smoking and estrogen-dependent diseases. Am J Epidemiol 1986; 123: 200.

'Sensen G F. Osteoporosis of the slender smoker revisited by epidemiologic approach. Eur J Clin Invest 1986; 16: $239-42$.

- Lau E, Donnan S, Barker D J P, Cooper C. Physical activity and calcium intake in fracture of the proximal femur in Hong Kong. Br Med J 1988; 297: 1441-43.

'Pagano R, Negri E, Decarli A, La Vecchia C. Smoking and weight in the 1983 Italıan National Health Survey. Int J Obesity 1987; 11: 333-38.

${ }^{10}$ Baron J A, La Vecchia C, Levi F. The anti-estrogenic effect of cigarette smoking in women. Am J Obstet Gynecol 1990; 162: 502-14.

"La Vecchia C, Decarli A, Fasoli M, Franceschi S, Gentile A, Negri E, Parazzıni F, Tognonı G. Oral contraceptives and cancers of the breast and of the female genital tract. Interim results from a case-control study. Br J Cancer 1986; 54: 311-7.

12 Townsend P, Davidson N Inequalities in Health: the Black Report. Harmondsworth, Penguin, 1982.

${ }^{13}$ Breslow N E, Day N E. Stattsical methods in cancer research. Vot. 1. The analysis of case-control studies. IARC Scientific Publication No 32, Lyon, 1980

${ }^{14}$ Mantel N, Haenszel W. Statistical aspects of the analysis of data from retrospective studies of disease. I Natl Cancer Inst 1959; 22: $719-48$.

${ }^{15}$ Mantel N. Chi-square tests with one degree of freedom; extensions of the Mantel-Haenszel procedure. J Amer Stat Ass 1963; 58: $690-700$.

${ }^{16}$ Baker R J, Nelder J A. The GLIM System. Release 3 Oxford, Numencal Algorithms Group, 1978.

${ }^{17}$ Hemenway D, Colditz G A, Willett W C, Stampfer M J, Speizer FE. Fractures and lifestyle: effect of cigarette smoking alcohol intake, and relative weight on the risk of hip and forearm fractures in middle-aged women Am J Publ Health 1988, 78: $1554-58$

's Resnik N M. Greenspan S L. 'Senile' osteoporosis reconsiderd. JAMA 1989; 261: 1025-9

"Hutchinson T A. Polansky S M, Feinsteın A R. Post-menopausal oestrogens protect against fractures of hip and distal radius. Lancer 1979; i: 705-9

${ }^{2}$ Weiss NS, Ure CL, Ballard JH, Williams A R, Daling J R. Decreased risk of fractures of the hip and lower forearm with postmenopausal use of estrogen. $N$ Engl J Med 1980; 303: 1195-8.

${ }^{21}$ Ettinger B, Genant H K, Cann LE. Long-term estrogen replacement therapy prevents bone loss and fractures. Ann Intern Med 1985; 102: 319-24

${ }^{2}$ Kiel D P, Felson D T, Anderson J J. Wilson P W F, Moskowitz M A. Hip fractures and the use of estrogen in postmenopausal women. N Engl J Med 1987; 317: 1169-74.

${ }^{23}$ Bikle D D, Genant H K, Cann C, et al. Bone disease in alcohol abuse. Ann Intern Med 1985; 103: 42-8.

${ }^{24}$ Spencer $H$, Rubio N, Rubıo E, Indreika M, Seitam A. Chronic alcoholism: frequently overlooked cause of osteoporosts in men Am J Med 1986: 80: 393-97.

${ }^{25}$ La Vecchia C. Pagano R. Negri E. Decarlı A. Determinants of alcohol consumption in Italy. Int J Epidemiol 1987; 16: 295-6.

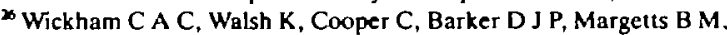
Morris J. Bruce S A. Dietary calcium, physical activity, and risk of hip fracture: a prospective study. Br Med J 1989; 299: $889-92$.

${ }^{7}$ Rothman K J. Modern epidemtology. Boston, Little Brown, 1986, p 359. 
${ }^{27}$ Negri E, Pagano R, Decarli A, La Vecehia C. Body weight and the prevalence of chronic diseases. I Epidemiol Comm Health 1988; 42: 24-29.

- Pearce N, Checkoway H. Case-control studies using other diseases as controls: problems of excluding exposure-related diseases. Am J Epidemiol 1988; 127: 851-6.

${ }^{30}$ Wacholder S, Silverman D. Re: Case control studies using other dis- eases as controls: problems of excluding exposure-related disease. Am J Epidemiol 1990; 132: 1017-8.

${ }^{31}$ Pearce N, Checkoway $H$. Case-control studies using other diseases as controls: problems of excluding exposure-related disenses (the authors reply). Am J Epidemiol 1990; 132: 1018-9.

(Revised version received January 1991) 